\title{
Amino acids and antioxidant activities of extracts from wild edible mushrooms from a community forest in the Nasrinual District, Maha Sarakham, Thailand
}

\author{
Thalisa YUWA-AMORNPITAK ${ }^{1 *}$ (D), Luchai BUTKHUP ${ }^{1}$, Pa-Nag YEUNYAW ${ }^{1}$
}

\begin{abstract}
Twenty two species of wild edible mushrooms were collected from Nasrinual community forest. The levels of 15 amino acids, antioxidant activity, and $\gamma$-aminobutyric acid (GABA) were determined. The 8 essential amino acids were arginine, histidine, isoleucine, leucine, lysine, phenylalanine, threonine, and valine, that they were found in all the mushrooms at concentration ranges of $0.28-2.14,0.11-0.8,0.19-1.33,0.33-2.22,0.22-1.73,0.18-1.09,0.31-1.83$, and $0.23-1.66 \mathrm{~g} / 100 \mathrm{~g}$ dw, respectively. The greatest and smallest amount of total amino acids, 28.41 and $5.76 \mathrm{~g} / 100 \mathrm{~g} \mathrm{dw}$, were found in Hed-Peung-No5 and Hed-Klum-Ma, respectively. The antioxidants from the mushroom extracts obtained by water and $60 \%$ methanol and their activities were evaluated. It was found that flavonoids content and DPPH in methanol extracts were higher than in water extracts. In contrast, the phenolic content and FRAP activity in water extracts were higher than those in methanol extracts. Total phenolic, FRAP, and flavonoids content were highest in the extracts of Hed-Peung-No2, but the DPPH activity was highest in the extracts from Hed-Peung-No3. The GABA content was higher in the extracts obtained by hot water than it was in the extracts obtained by methanol. The highest GABA content was from water extract of Hed-Sai-duan $(23.304 \pm 0.027 \mathrm{mg} / \mathrm{g} \mathrm{dw})$.
\end{abstract}

Keywords: DPPH; total phenolic compounds; flavonoids; FRAP; GABA.

Practical Application: Wild edible mushrooms were collected from Nasrinual community forest, and identified by morphology. Amino acids were analyzed from 22 mushroom species by HPLC. Type of extraction solvent (water and methanol) had an influence on the level and type of antioxidant activities including GABA content.

\section{Introduction}

In addition to sources of various aromatic flavors, including umami, mushrooms are also healthy foods. They are rich in protein, vitamins, and minerals and low in calories and fat (Akindahunsi \& Oyetayo, 2006). Some kinds of mushrooms have good flavor, such as shitake and truffles. The typical mushroom aroma comes from $\mathrm{C}_{8}$ volatile compounds, namely, oct-1-en-3-ol, oct-1-en-3-on, octan-3-ol, and octan-3-on (Moliszewska, 2014). Mushrooms have been used as foods and food flavorings for a long time. Furthermore, some mushrooms produce secondary metabolites, such as lovastatin, $\gamma$-aminobutyric acid (GABA), and ergothioneine (Chen et al., 2012). Lovastatin, mostly produced by Monascus species, inhibits the enzyme necessary for cholesterol production, thereby reducing LDL cholesterol levels and the risk for developing coronary heart disease (Aaron et al., 2007). GABA is often used to treat blood pressure, stress and anxiety and to improve sleep, as well as to stimulate the body's natural growth hormone. Ergothioneine is an amino acid (the derivative of histidine) that has excellent antioxidant properties and is good for health (Cheah \& Halliwell, 2012). Furthermore, mushrooms are also sources of beneficial bioactive substances, such as $\beta$-glucan, flavonoids, glycoproteins, sesquiterpenes, carotene, and phenolic compounds (Reis et al., 2011). These secondary metabolites are effective antioxidants that enhance human health.
The amino acid level is an indicator of the nutritional value and flavor of food. The types of amino acids that influence the taste of mushrooms include alanine, glycine, serine, and threonine, which are sweet amino acids, and arginine, leucine, isoleucine, histidine, methionine, phenylalanine, and valine, which are bitter amino acids. The tasteless amino acids are lysine and tyrosine (Kalač, 2016; Pomeranz, 2012). Mushrooms constitute a source of nine essential amino acids (histidine, isoleucine, leucine, lysine, methionine, phenylalanine, threonine, tryptophan, and valine) that humans cannot synthesize. These nine amino acids are also found in the oyster mushroom species Pleurotus ostreatus and $P$. sajor-caju, which have amino acids totaling 21.10 and $20.12 \mathrm{mg} / \mathrm{g}$ fresh weight, respectively (Chirinang \& Intarapichet, 2009). Leucine, threonine and valine are the three most abundant essential amino acids.

Due to mushrooms are rich of protein, antioxidant and also good taste and flavor profile. They can be used in meat product to replacement animal protein such as smoke sausages with a desirable nutritional properties and acceptable sensory (Nagy et al., 2017). However wild edible mushrooms that are abundant only in rainy season. In order to preserve for long time storage, gamma irradiation was applied to dried and sliced sample of Boletus edulis. It was found that nutritional, chemical compositions and antioxidants of the slide mushroom slightly decreased for long storage to 12 months (Fernandes et al., 2017). One reported 
(Falandysz et al., 2019) investigation on contamination with mercury of a raw and stir-fried mushrooms (Boletaceae Family). All mushrooms that grown on polymetallic soil (accumulate $\mathrm{Hg}$ in elevated concentration) were collected from the region of west-central Yunnan, China. The results showed that if taken fried mushroom daily over a week period (100g x 7) could provide $\mathrm{Hg}$ in dose from 1.9 to $9.6 \mu \mathrm{g} / \mathrm{kg}$ bm (body mass). The consumption of fried mushrooms could provide $\mathrm{Hg}$ in the safe dose. The accumulation radiocesium of two species mushroom from Chernobyl fallout contaminated area by Chiaravalle et al. (2018) was observed. They found that Boletus edulis was more contaminated with cesium-137 than Amanita caesarea. However the consumption of both mushrooms proved to be non-dangerous for humans.

The aim of this study was to collect and identify wild edible mushrooms from the Nasrinual community forest. The amounts of amino acids from dried mushrooms were evaluated, and the antioxidant activity in the water and methanol extracts of these wild mushrooms was determined by their phenolic content, their ability to scavenge DPPH free radicals, and the amounts of FRAP, GABA, and flavonoids they contained.

\section{Material and methods}

\subsection{Mushroom collection and extraction}

Wild mushrooms were collected from the forest in the Nasrinual District, Maha Sarakham, Thailand. All the samples were kept in cooler with ice and transported to the laboratory. The morphological features of the mushrooms were studied and identified. Each type of fruiting body was individually dried at $50{ }^{\circ} \mathrm{C}$, ground into powder and kept in plastic zip-locked bags. The stored mushroom powder was kept in a refrigerator until used in experiments. A total of $0.1 \mathrm{~g}$ of dried mushroom was used to create an extract in $5 \mathrm{~mL}$ water and an extract in $60 \%$ methanol by sonication for $1 \mathrm{~h}$. The clear supernatant was generated by centrifugation at $10,000 \mathrm{~g}$ and kept at $-20^{\circ} \mathrm{C}$ until analyzed.

\subsection{Antioxidant activity of the mushroom extracts}

The total phenol content in the mushroom extracts obtained by water and by $60 \%$ methanol were determined by Folin-Ciocalteu reagent (Miliauskas et al., 2004). Each mushroom extract sample $(250 \mu \mathrm{L})$ was mixed with $2.5 \mathrm{~mL}$ Folin-Ciocalteu reagent diluted in distilled water (1:10). Then, $2 \mathrm{~mL}$ of $1 \mathrm{M} \mathrm{Na}_{2} \mathrm{CO}_{3}$ was added, and after it was mixed well, the solution was kept in the dark for $15 \mathrm{~min}$ before the absorbance was measured at $765 \mathrm{~nm}$. Gallic acid at various concentrations $(200-1000 \mu \mathrm{g} / \mathrm{mL})$ was prepared to generate data for the standard curve. The results are expressed in $\mathrm{mg}$ of gallic acid equivalent per gram of dried mushrooms (mg GAE/g dw).

The total flavonoid content of the mushroom extracts obtained by water and by $60 \%$ methanol were determined by aluminum chloride solution (Soares et al., 2017). Each mushroom extract sample $(150 \mu \mathrm{L})$ was mixed with $100 \mu \mathrm{L}$ of $5 \% \mathrm{NaNO}_{2}$ for $6 \mathrm{~min}$. Then, $150 \mu \mathrm{L}$ of $10 \% \mathrm{AlCl}_{3}$ was added, and the mixture was maintained for $5 \mathrm{~min}$. Then, $650 \mu \mathrm{L}$ of $1 \mathrm{M}$ $\mathrm{NaOH}$ was added before measuring the absorbance at $510 \mathrm{~nm}$. Rutin at concentrations between 200 and $1000 \mu \mathrm{g} / \mathrm{mL}$ was used to prepare the standard curve. The total flavonoid content was determined in $\mathrm{mg}$ of rutin equivalent per gram of mushroom dry weight (mg RE/g dw).

\subsection{Scavenging activity}

The scavenging activity of the mushroom extracts was determined by DPPH radical scavenging (Chen et al., 1999). Briefly, each mushroom extract sample $(200 \mu \mathrm{L})$ was mixed with $1.8 \mathrm{~mL}$ of DPPH solution (3.94 mg of 2,2-diphenyl-1-picrylhydrazyl dissolved in $50 \mathrm{~mL}$ of $50 \%$ ethanol). The mixture was kept in the dark for $10 \mathrm{~min}$ before the absorbance was measured at $517 \mathrm{~nm}$. Ascorbic acid (10-50 $\mu \mathrm{g} / \mathrm{mL})$ was used as a reference compound. The absorbance was converted into the percentage of radical scavenging capacity by the following Equation 1:

$D P P H$ scavenging $(\%)=\frac{D P P H_{\text {control }}-\left(\text { Sample }_{\text {control }}-A_{\text {sample }}\right)}{D P P H_{\text {control }}} \times 100$

where: $\mathrm{DPPH}_{\text {control }}$ is the absorbance of the DPPH solution; Sample $_{\text {control }}$ is the absorbance of the mushroom extract in reaction with the $\mathrm{DPPH}$ solution; and $\mathrm{A}_{\text {sample }}$ is the absorbance of the mushroom extract.

The DPPH radical scavenging activity was reported as the mg ascorbic acid equivalent (AAE) per gram of mushroom dry weight (mg AAE/g dw).

\subsection{Ferric Reducing Antioxidant Power (FRAP)}

The reducing power of the mushroom extracts was determined by ferric-TPTZ reagent (Fu et al., 2010). Acetate buffer (0.25 M) was prepared by adding $30 \mu \mathrm{L}$ of acetic acid in sodium acetate solution (41 mg), and the $\mathrm{pH}$ was adjusted to 3.6 before the volume was increased to $1000 \mathrm{~mL}$. Ten millimolar TPTZ (2,4,6-Tris(2-pyridyl)-s-triazine) was prepared by dissolving $624.66 \mathrm{mg}$ in a small volume of $\mathrm{HCl}$ and adjusting the volume to $200 \mathrm{~mL}$ with $0.25 \mathrm{M}$ acetate buffer. Ferric chloride $(20 \mathrm{mM})$ was generated by dissolving $1.0812 \mathrm{~g}$ of $\mathrm{FeCl}_{3} 6 \mathrm{H}_{2} \mathrm{O}$ in $0.25 \mathrm{M}$ acetate buffer and adjusting the volume to $200 \mathrm{~mL}$. The FRAP reagent was prepared by mixing $25 \mathrm{~mL}$ of acetate buffer with $2.5 \mathrm{~mL}$ of TPTZ solution and $2.5 \mathrm{~mL}$ of ferric chloride. The reagent mixture was incubated at $37^{\circ} \mathrm{C}$ for $15 \mathrm{~min}$ before use, as it must be freshly prepared. Ascorbic acid $(0-35 \mu \mathrm{g} / \mathrm{mL})$ in water was used as a standard solution in this assay and was generated by mixing $150 \mu \mathrm{L}$ of each concentration with $2.85 \mathrm{~mL}$ of FRAP reagent. The mixture was kept in the dark for $30 \mathrm{~min}$, and its absorbance was measured at $590 \mathrm{~nm}$. The FRAP value was measured based on the calibration curve of the ascorbic acid. The FRAP values were reported as a microgram of ascorbic acid equivalent per gram of mushroom dry weight ( $\mu \mathrm{g} \mathrm{AAE} / \mathrm{g} \mathrm{dw}$ ).

\subsection{GABA ( $\gamma$-aminobutyric acid) determination}

The GABA content was determined by spectrophotometry (Karladee \& Suriyong, 2012). Borate buffer was prepared by dissolving $2.54 \mathrm{~g}$ borax into $4.7 \mathrm{~g}$ boric acid and adjusting the volume to $1000 \mathrm{~mL}$. Phenol (6\%) was prepared by dissolving $6 \mathrm{~mL}$ phenol in $100 \mathrm{~mL}$ distilled water. The $6 \%$ sodium hypochlorite was prepared by adding $6 \mathrm{~g} \mathrm{NaClO}$ into $100 \mathrm{~mL}$ distilled water. 
The reaction was as follows: each $0.5 \mathrm{~mL}$ of mushroom extract was mixed with $0.5 \mathrm{~mL}$ of borate buffer, $0.5 \mathrm{~mL}$ of $6 \%$ phenol and $1.5 \mathrm{~mL} 6 \%$ sodium hypochlorite. This mixture was boiled for $10 \mathrm{~min}$ and cooled before the absorbance was measured at $630 \mathrm{~nm}$. The standard GABA $\left(\gamma-\mathrm{C}_{4} \mathrm{H}_{9} \mathrm{NO}_{2}\right)$ solution was prepared by dissolving $0.1 \mathrm{~g}$ in $100 \mathrm{~mL}$ distilled water $(1000 \mu \mathrm{g} / \mathrm{mL})$. Concentrations between 200 and $1000 \mu \mathrm{g} / \mathrm{mL}$ were analyzed and used to create the standard curve. The GABA content is reported as $\mathrm{mg} / \mathrm{g} \mathrm{dw}$.

\subsection{Amino acid determination}

The amino acid profile of the mushrooms was measured by HPLC (Wandelen \& Cohen, 1997). The mushroom powder was digested with $5 \mathrm{~mL}$ of $6 \mathrm{~N} \mathrm{HCl}$ in a $110^{\circ} \mathrm{C}$ heating block for $22 \mathrm{~h}$. The internal standard was filtered and diluted with distilled water. The sample was filtered through a $0.45 \mu \mathrm{m}$ membrane filter. The mixture was mixed with AccQ-fluor derivatization buffer and AccQ-fluor reagent to obtain amino acid derivatives. The samples were heated at $55^{\circ} \mathrm{C}$ for $10 \mathrm{~min}$ and measured by HPLC (Water Alliance 2695) using sodium acetate buffer in the mobile phase. The temperature of the column (Hypersil gold column C18 Z4.6*150 mm, $3 \mu \mathrm{m}$ ) was adjusted to $30^{\circ} \mathrm{C}$. A Jasco FP2020 fluorescence detector (EX: 250, EM: $395 \mathrm{~nm}$ ) was used. H-STD (Sigma) was used for the amino acid standards.

\subsection{Statistical analysis}

The results of all experiments were reported as the mean \pm standard deviation of three replicates. The results were evaluated using ANOVA (SPSS version 15.0) with $\alpha<0.05$.

\section{Results and discussion}

\subsection{Wild mushroom identification based on morphology}

Twenty-two species of wild edible mushrooms were collected from the Nasrinual community forest. Based on morphology studies (Chandrasrikul et al., 2008), the species were placed in 9 families: Russulaceae (8), Boletaceae (5), Tricholomataceae (2), Agaricaceae (1), Amanitaceae (1), Pluteaceae (1), Auriculariaceae (1), Hymeogasteraceae (1), Diplocystaceae (1) and Sclerodermataceae (1), as shown in Table 1. Most of these species are well known and have been consumed by the local people for a long time. However, one species of Scleroderma sp. had first been found in northeast Thailand. It has a unique and pleasant odor that is different than that of other species of edible mushrooms. Although the mushrooms are abundant in the rainy season, between June and September, of each year, in some years, when rainfall is plentiful through October, these mushrooms found in the Nasrinual forest. Various types of edible mushrooms are collected by mushroom hunters for their own use and for sale. Figure 1 shows some edible mushrooms collected from the Nasrinual community forest.

\subsection{Antioxidant activity}

\section{$D P P H$ free radical scavenging}

Free radical scavenging activity by the mushroom extracts obtained by water and $60 \%$ methanol were determined by the $\mathrm{DPPH}$ reagent. The DPPH • radical (purple) accepts an electron or hydrogen radical from antioxidant molecules. Upon electron transfer, the color changes from purple to yellow. Figure 2 shows the DPPH radical scavenging activity of the mushroom

Table 1. Mushrooms collected from the community forest in the Nasrinual District.

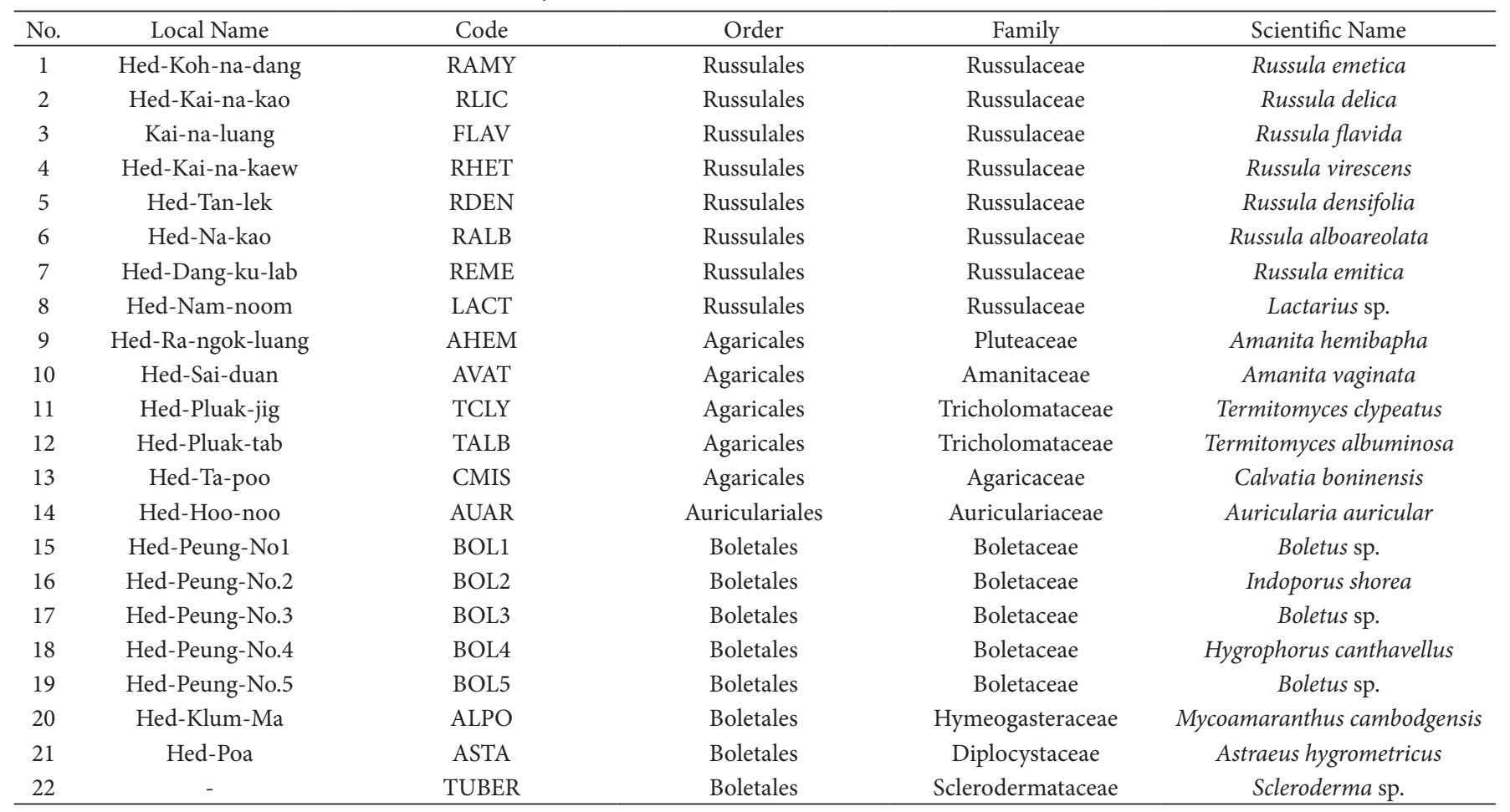




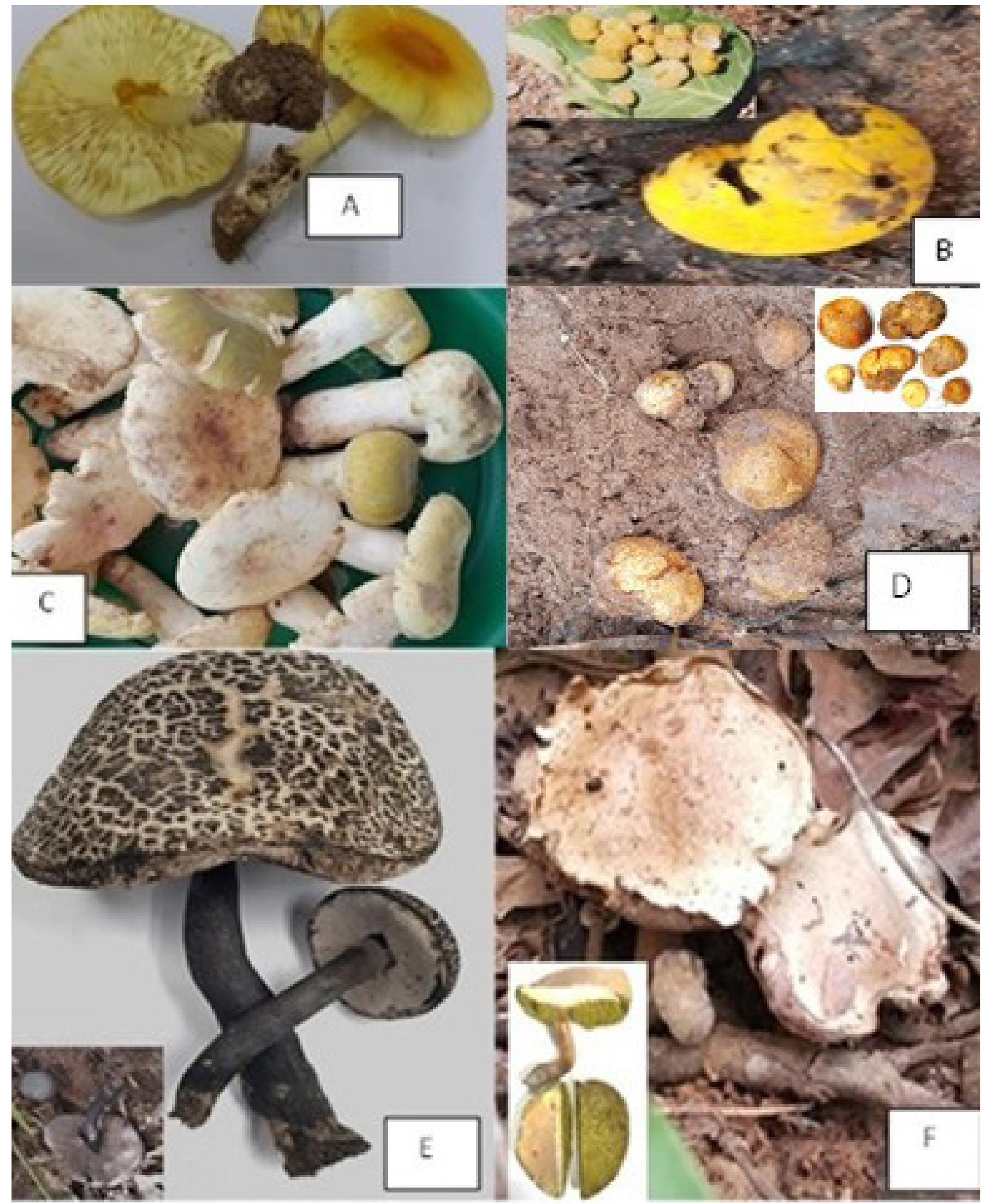

Figure 1. Some wild edible mushrooms collected from Nasrinual community forest. (A) AHEM; (B) ALPO; (C) RHET; (D) TUBER; (E) BOL2; (F) BOL3. 
extracts obtained by water and methanol. It was found that the methanol extracts (1.79-34.98 $\mathrm{mg} \mathrm{AAE} / \mathrm{g} \mathrm{dw})$ had higher activity than the water extracts (1.91-12.58 $\mathrm{mg} \mathrm{AAE} / \mathrm{g} \mathrm{dw}$ ). This result was in agreement with the studies performed by Gan et al. (2013), and Boonsong et al. (2016). The highest value was from Hed-Peung-No.3 (BOL3) at $34.98 \pm 0.2833 \mathrm{mg} \mathrm{AAE} / \mathrm{g} \mathrm{dw}$. The second highest level of DPPH scavenging radical activity was found in the methanol extract from Hed-Klum-Ma (ALPO) at $24.01 \pm 0.2341 \mathrm{mg} \mathrm{AAE} / \mathrm{g} \mathrm{dw}$. Hed-Hoo-noo (AUAR) is a type of jelly fungi, and the extracts from it had the lowest DPPH scavenging activity at $1.69 \pm 0.061$ and $2.34 \pm 0.038 \mathrm{mg} / \mathrm{g} \mathrm{dw}$ for the water and methanol extracts, respectively. In addition, the DPPH scavenging activity in the extract of Boletaceae was higher than that in the samples from the other families, as shown in Figure 2.

\section{Total phenolic content}

In contrast with the results of the DPPH scavenging assay, most of the phenolic contents in the wild mushroom water extracts were higher than those in the methanol extracts. The total phenolic content in the water and methanol extracts was between 8.14-141.18 and 1.56-97.32 mg GAE/g dw, respectively. The highest total phenolic content was found in the water and methanol extracts of Hed-Peung-No.2 at $141.18 \pm 1.274$, and $97.317 \pm 0.806 \mathrm{mg} \mathrm{GAE} / \mathrm{g} \mathrm{dw}$, respectively (Figure 3 ). The lowest total phenolic content was in the water and methanol extract of Hed-Hoo-noo (AUAR) at $8.94 \pm 0.171$ and $1.56 \pm 0.069 \mathrm{mg} \mathrm{GAE} / \mathrm{g} \mathrm{dw}$, respectively. In this study, the total phenolic content of the water extract was higher than that of the methanol extract, which was consistent with

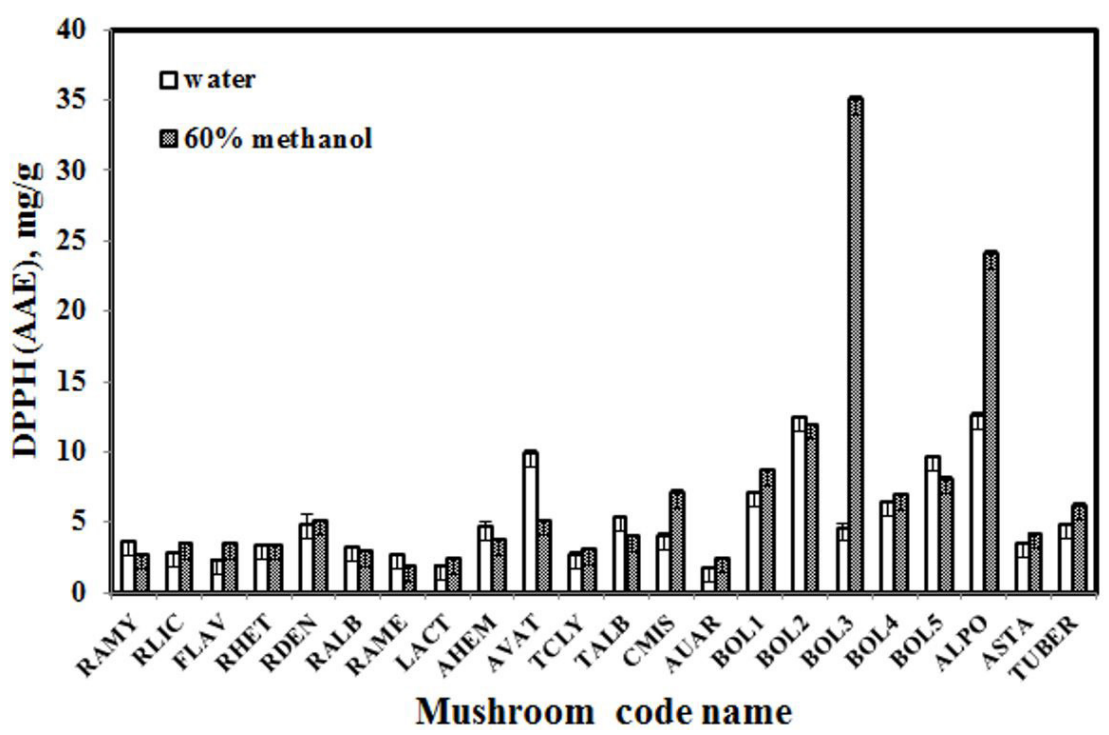

Figure 2. DPPH scavenging activity of the edible mushroom extracts obtained by water and $60 \%$ methanol; vertical bars indicate the standard deviation $(n=3)$.

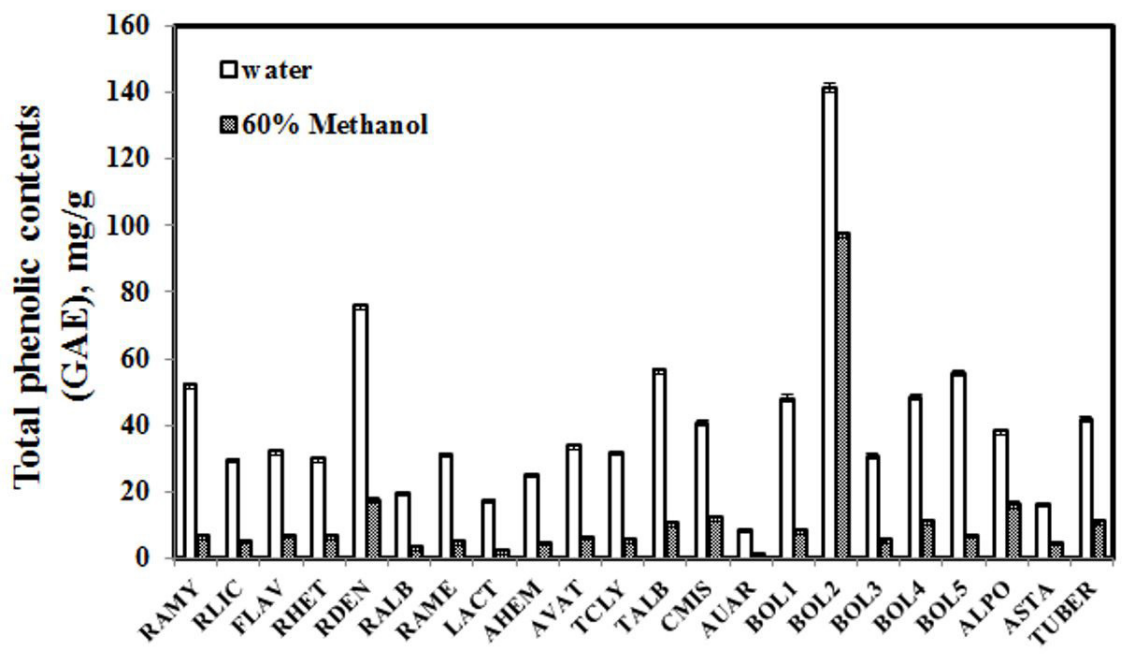

Mushrooms code name

Figure 3. Total phenolic content in mushroom extracts obtained by water and $60 \%$ methanol; vertical bars indicate the standard deviation $(n=3)$. 
the finding of Boonsong et al. (2016). Furthermore, the total phenolic content in some species of the wild mushrooms (RAME, RDEN, TALB, CMIS, BOL1, BOL2, and BOL3) was higher than that of cultivated mushrooms (Lentinus edodes, Volvariella volvacea, Pleurotus eous, Pleurotus sajor-caju, and Auricularia auricular).

\section{Reducing power as determined by the FRAP method}

The results of the reducing power assay by the RFAP method for the mushroom extracts obtained by water and methanol are shown in Figure 4. It was found that the FRAP value for the water extract was higher than it was for the methanol extract at 1.76-15.00 and 0.815-14.19 mg AAE/g, respectively. The reducing power of the water extract from
ALPO was the highest at $15.00 \pm 0.405 \mathrm{mg} \mathrm{AAE} / \mathrm{g} \mathrm{dw}$. The highest reducing power among the methanol extracts was $14.19 \mathrm{mg} \mathrm{AAE} / \mathrm{g} \mathrm{d}$ w from Hed-Peung-No.2. This study revealed that the FRAP value for the mushroom extract obtained by water was higher than for the extract obtained by methanol. Chirinang \& Intarapichet (2009) and Puttaraju et al. (2006) also reported that the FRAP values of Pleurotus ostreatus and $P$. sajor-caju water extracts were higher than those of their ethanol extracts.

\section{Total flavonoid contents}

Figure 5 shows the total flavonoid content in the mushroom extracts. The results indicated that the flavonoid content in the mushroom extract obtained by methanol was slightly

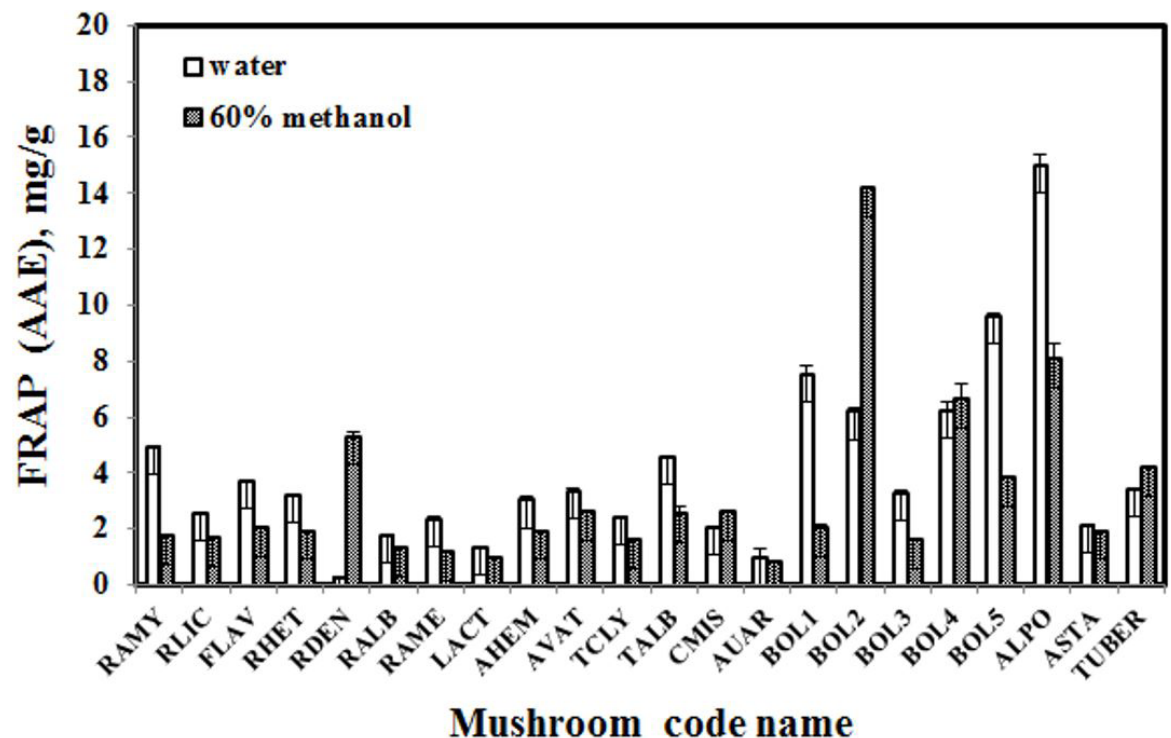

Figure 4. Reducing power determined by FRAP method on mushroom extracts obtained by water and $60 \%$ methanol in terms of ascorbic acid equivalency (AAE); vertical bars indicate the standard deviation $(n=3)$.

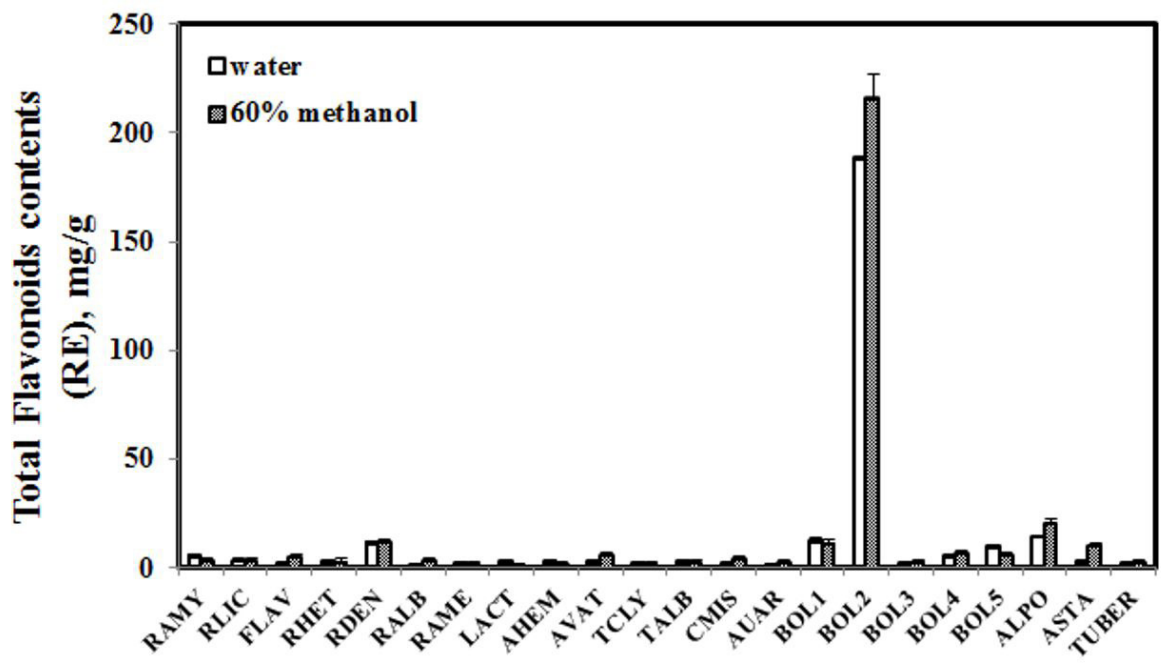

Mushroom code name

Figure 5. Total flavonoid content of mushroom extracts obtained by water and $60 \%$ methanol; vertical bars indicate the standard deviation $(\mathrm{n}=3)$. 
higher than that in the extract obtained by water. These results were similar to those of Gan et al. (2013), who also found that the flavonoid content of Brazilian and button mushroom in extracts obtained by methanol was higher than that of extracts obtained by water. In this study, the total flavonoid content of all mushroom extracts, obtained by both methanol and water, was relatively low. The flavonoid content in the water extracts were between 0.88 and $188.43 \mathrm{mg} \mathrm{RE} / \mathrm{g}$ $\mathrm{dw}$, and that in the $60 \%$ methanol extracts were between 1.72 and $216.46 \mathrm{mg} \mathrm{RE} / \mathrm{g} \mathrm{dw}$. The highest flavonoid content was in Hed-Peung-No.2 (BOL2), in which it was higher in the methanol extract compared to the water extract, but it was low in most of the mushrooms.

\section{$\gamma$-Aminobutyric acid (GABA)}

GABA content was also determined for the mushroom extracts by water and methanol. The results are shown in Table 2 . The GABA content was higher in the water extracts than it was in the methanol extracts. The highest GABA level was found in the water extract of Hed-Sai-duan at $23.304 \pm 0.027 \mathrm{mg} / \mathrm{g} \mathrm{dw}$, and the lowest GABA level was found in the methanol extract of Hed-Sai-duan at $0.999 \pm 0.072 \mathrm{mg} / \mathrm{g} \mathrm{dw}$. Chen et al. (2012) studied GABA from the fruiting body and mycelium of various mushrooms. They found that the fruiting bodies of Flammulina velutipes and Boletus edulis contained the greatest amounts of GABA ( 0.229 and $0.202 \mathrm{mg} / \mathrm{g} \mathrm{dw}$, respectively). In contrast, mycelia from Cordyceps cicadae contained the highest GABA content at $0.254 \mathrm{mg} / \mathrm{g} \mathrm{dw}$. This finding indicated that wild edible mushrooms are a good source of GABA.

\section{Amino acids}

Mushrooms are well known as high protein sources. Furthermore, all types of essential amino acids are found in mushrooms. Due to the method used to determine the amino acids in this study, only 15 types of essential amino acids were found; 8 of them were essential amino acids (EAAs), and 7 were non-essential amino acids. The eight EAAs were arginine, leucine, isoleucine, lysine, valine, threonine, phenylalanine, and histidine. Nonessential amino acids included aspartic acid, serine, glutamic acid, glycine, alanine, proline and tyrosine. All types of amino acids in these mushrooms are shown in Table 3. The amount of amino acid detected was between 0.11 and $5.66 \mathrm{~g} / 100 \mathrm{~g}$ dried weight. Glutamic acid was found in the greatest amounts in the mushrooms at $0.77-5.66 \mathrm{~g} / 100 \mathrm{~g}$. These results correspond with the report of Kouassi et al. (2016) that indicated that glutamic acid and valine are the most predominant amino acids in R. lepida, $R$. mustelina and, $R$. delica. However, a food protein is expected to have a high ratio of essential amino acids to total amino acids. In this study, the EAA:total amino acid ratio was 0.389-0.462. The high ratio of essential amino acid:total amino acid indicated that these mushrooms have a high protein content. In this study, only Hed-Klum-Ma had a low essential amino acid:total amino acid ratio (0.389).

Table 2. Total amino acid and GABA analysis of wild mushroom extracts obtained bywater and methanol.

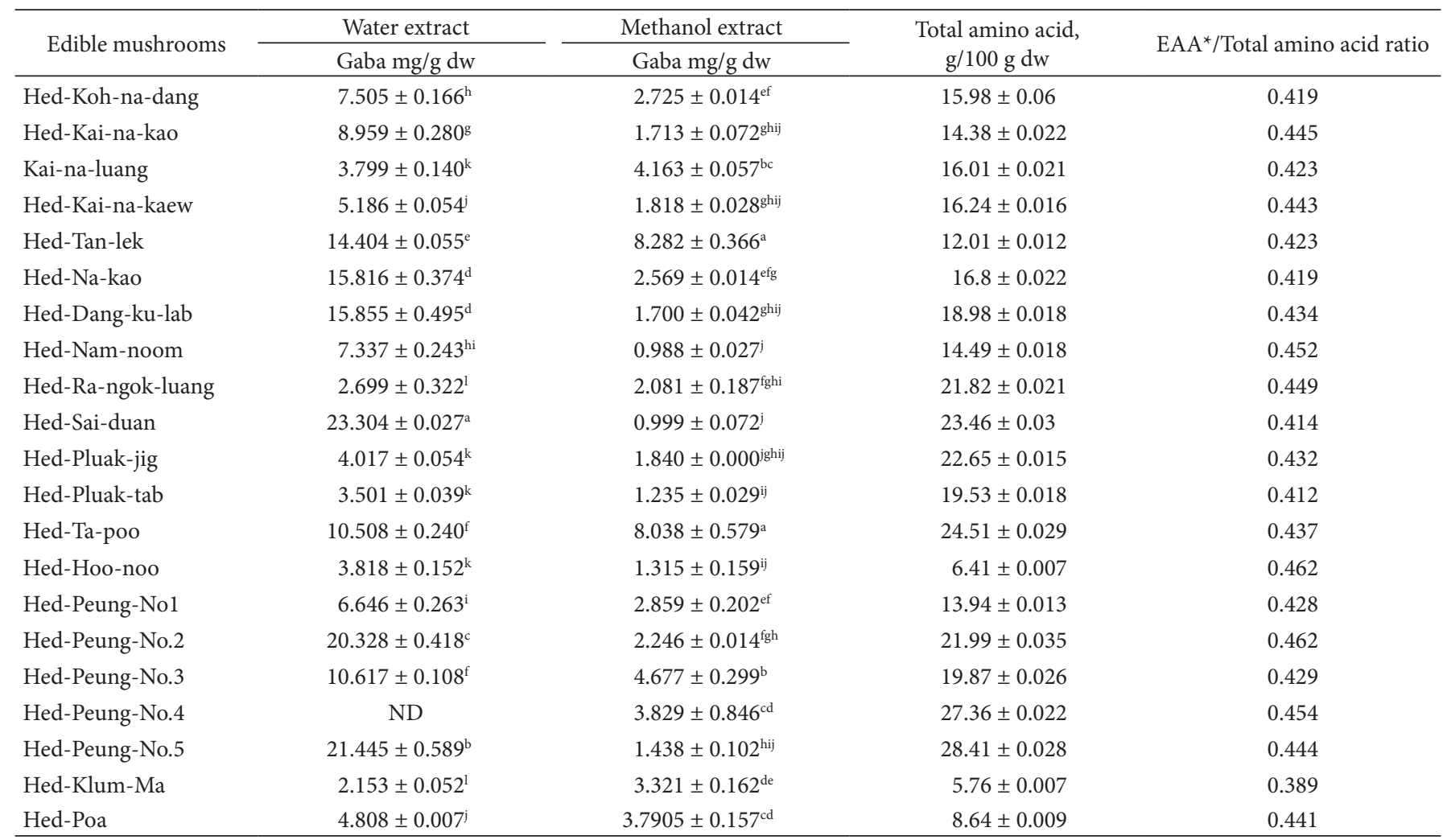

${ }^{*} \mathrm{EAA}=$ Essential amino acid; ND $=$ Not Detected. Means followed by same letter in the same column are not significantly different ( $\mathrm{p}<0.05$ according to Duncan's test). Data are presented as the mean \pm standard deviation of three replicates $(n=3)$. 


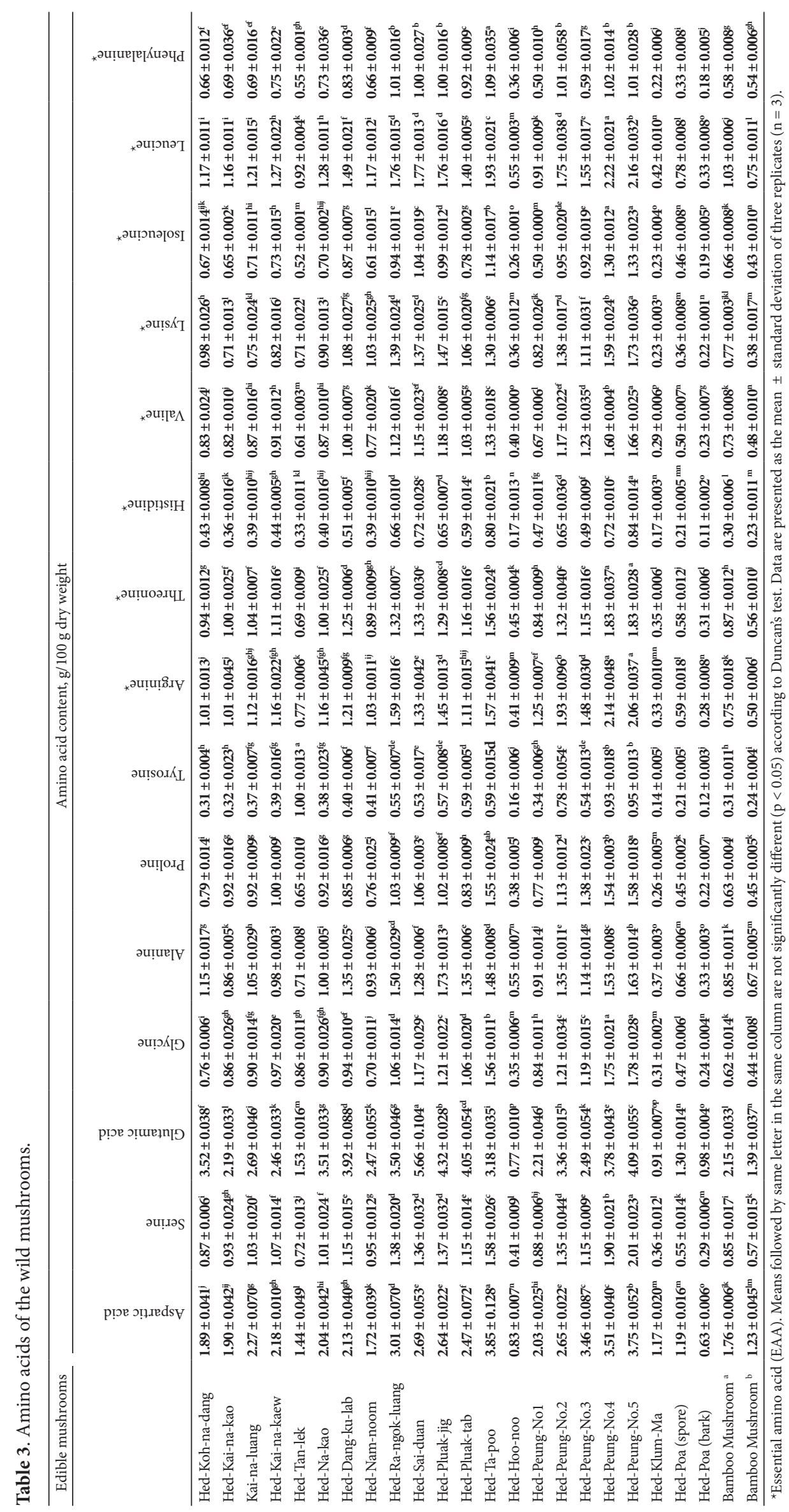




\section{Conclusion}

These findings show that the wild edible mushrooms in the Nasrinual community forest are not only highly diverse but also of high nutritional value, which is consistent with their use as food sources for a long time. Wild edible mushrooms contain essential amino acids and substantial glutamic acid, imparting an umami taste. Various antioxidant activities and high levels of GABA were also found in the wild edible mushrooms. Therefore, they are good for human health.

\section{Acknowledgements}

We appreciate the plant genetic conservation project under the Royal Initiative of Her Royal Highness Princess Maha Chakri Sirindhorn, Mahasarakham University (grant No. 6105056) and also thank the Faculty of Technology for providing financial support.

\section{References}

Akindahunsi, A. A., \& Oyetayo, F. L. (2006). Nutrient and antinutrient distribution of edible mushroom, Pleurotus tuber-regium (fried) singer. Lebensmittel-Wissenschaft + Technologie, 39(5), 548-553. http://dx.doi.org/10.1016/j.lwt.2005.04.005.

Aarons, C. B., Cohen, P. A., Gower, A., Reed, K. L., Leeman, S. E., Stucchi, A. F., \& Becker, J. M. (2007). Strain (HMG-CoA reductase inhibitors) decrease postoperative adhesions by increasing peritoneal gibrinolytic activity. Annals of Surgery, 245(2), 176-184. http:// dx.doi.org/10.1097/01.sla.0000236627.07927.7c. PMid:17245169.

Boonsong, S., Klaypradit, W., \& Wilaipun, P. (2016). Antioxidant activities of extracts from five edible mushrooms using different extractants. Agriculture and Natural Resources, 50(2), 89-97. http:// dx.doi.org/10.1016/j.anres.2015.07.002.

Chandrasrikul, A., Suwanarit, P., Sangwanit, U., Morinaga, T., Nishizawa, Y., \& Murakami, Y. (2008). Diversity of mushrooms and macrofungi in Thailand. Bangkok, Thailand; Kasetsart University Publisher.

Cheah, I. K., \& Halliwell, B. (2012). Ergothionine: antioxidant potential, physiological function and role in disease. Biochimica et Biophysica Acta, 1822(5), 784-793. http://dx.doi.org/10.1016/j.bbadis.2011.09.017. PMid:22001064.

Chen, S.Y., Ho, Y.J., Hsieh, Y.J., Wang, L.T., \& Mau, J.L. (2012). Contents of lovastatin, $\Upsilon$ - aminobutyric acid and ergothionine in mushroom fruiting bodies and mycelia. LWT-Food Science and Technology, 47, 274-278.

Chen, Y., Wang, M.F., Rosen, R.T., \& Ho, C.T. (1999). 2,2-Diphenyl-1picrylhydrazyl radical scavenging active component from Polygonium multiforum Thunb. Journal of Natural Products, 47, 2226-2228.

Chiaravalle, A. E., Mangiacotti, M., Marchesani, G., Bortone, N., Tomaiuolo, M., \& Trotta, G. (2018). A ten-year survey of radiocontamination of edible Balkan mushrooms: Cs-137 activity levels and assessed dose to the population. Food Control, 94, 263-267. http://dx.doi. org/10.1016/j.foodcont.2018.05.045.

Chirinang, P., \& Intarapichet, K. (2009). Amino acids and antioxidant properties of the oyster mushrooms, Pleurotus ostreatus and Pleurotus sajor-caju. Science Asia, 35(4), 326-331. http://dx.doi.org/10.2306/ scienceasia1513-1874.2009.35.326.
Falandysz, J., Zhang, J., Medyk, M. M., \& Zhang, X. (2019). Mercury in stir-fried and raw mushrooms from the Boletaceae family from the geochemically anomalous region in the Midu county, China. Food Control, 102, 17-21. http://dx.doi.org/10.1016/j.foodcont.2019.03.007.

Fernandes, A., Barreira, J. C. M., Günaydi, T., Alkan, H., Antonio, A. L., Oliveira, M. B. P. P., Martins, A., \& Ferreira, I. C. F. R. (2017). Effect of gamma irradiation and extended storage on selected chemical contituents and antioxidant activities of sliced mushroom. Food Control, 72, 328-327. http://dx.doi.org/10.1016/j.foodcont.2016.04.044.

Fu, L., Xu, B. T., Xu, X. R., Qin, X. S., Gan, R. Y., \& Li, H. B. (2010). Antioxidant capacities and total phenolic contents of wild fruits from South China. Molecules, 15(12), 8602-8617. http://dx.doi. org/10.3390/molecules15128602. PMid:21116229.

Gan, C. H., Nural, A. B., \& Asmah, R. (2013). Antioxidant analysis of different types of edible mushrooms (Agaricus bisporous and Agaricus brasiliensis). International Food Research Journal, 20(3), 1095-1102.

Kalač, P. (2016). Edible mushrooms: chemical composition and nutrition value. London Wall: Elsevier.

Karladee, D., \& Suriyong, S. (2012). $\Upsilon$-Aminobutyric acid (GABA) content in different varieties of brown rice during germination. ScienceAsia, 38(1), 13-17. http://dx.doi.org/10.2306/scienceasia1513-1874.2012.38.013.

Kouassi, K. A., Konan, K. H., Kouadio, E. J. P., Due, A. E., \& Kouame, L. P. (2016). Proximate composition, minerals and amino acids profiles of selected wild edible Russula species from Côte d'Ivoire. Turkish Journal of Agriculture-Food Science and Technology, 4(10), 882-886. http://dx.doi.org/10.24925/turjaf.v4i10.882-886.816.

Miliauskas, G., Venskutonis, P. R., \& van Beek, T. A. (2004). Screening of radical scavenging activity of some medicinal and aromatic plant extracts. Food Chemistry, 85(2), 231-237. http://dx.doi.org/10.1016/j. foodchem.2003.05.007.

Moliszewska, E. (2014). Mushroom flavor. Acta Universitatis Lodziensis. Folia Biologica et Oecologica, 10(1), 80-88. http://dx.doi.org/10.2478/ fobio-2014-0007.

Nagy, M., Semeniuc, C. A., Socaci, S. A., Pop, C. R., Rotar, A. M., Salagean, C. D., \& Tofana, M. (2017). Utilization of brewer's spant grain and mushrooms in fortification of smoked sausages. Food Science and Technology, 37(2), 315-320. http://dx.doi.org/10.1590/1678-457x.23816.

Pomeranz, Y. (2012). Functional properties offood components. Cambridge: Academic Press.

Puttaraju, N. G., Venkateshaiah, S. U., Dharmesh, S. M., Urs, S. M., \& Somasundaram, R. (2006). Antioxidant activity of indigeneous edible mushrooms. Journal of Agricultural and Food Chemistry, 54(26), 229-235. http://dx.doi.org/10.1021/jf0615707. PMid:17177499.

Soares, L. A. L., Ramos, R. T. M., Bezerra, I. C. F., \& Ferreira, M. R. A. (2017). Spectrophotometric quantification of flavonoids in herbal material, crude extract, and fractions from leaves of Eugenia uniflora Linn. Pharmacognosy Research, 9(3), 253-256. http://dx.doi. org/10.4103/pr.pr_143_16. PMid:28827966.

Reis, F. S., Pereira, E., Barros, L., Sousa, M. J., Martins, A., \& Ferreira, I. C. (2011). Biomolecule profiles in inedible wild mushrooms with antioxidant value. Molecules, 16(6), 4328-4338. http://dx.doi. org/10.3390/molecules16064328. PMid:21613974.

Wandelen, C.V., \& Cohen, S.A. (1997). Using quaternary highperformance liquid chromatography eluent systems for separating 6-aminoquinolyl-N- hydroxysuccinimidyl carbamate-derivatized amino acid mixtures. Journal of Chromatography A, 763(1-2), 11-22. 